\title{
Thermal and optical properties of $\mathrm{Cd}_{2} \mathrm{SnO}_{4}$ thin films using photoacoustic spectroscopy
}

\author{
K. Jeyadheepan - P. Palanichamy • V. Swaminathan • \\ M. Jayachandran • C. Sanjeeviraja
}

Received: 23 April 2009 / Accepted: 4 November 2009 / Published online: 26 November 2009

(C) Springer-Verlag 2009

\begin{abstract}
Cadmium stannate $\left(\mathrm{Cd}_{2} \mathrm{SnO}_{4}\right)$ thin films were prepared by the RF magnetron sputtering technique on glass substrates with substrate temperatures of room temperature (RT), $100^{\circ} \mathrm{C}, 200^{\circ} \mathrm{C}$ and $300^{\circ} \mathrm{C}$. Photoacoustic analyses were made to obtain the thermal diffusivity and the optical bandgap values of the $\mathrm{Cd}_{2} \mathrm{SnO}_{4}$ thin films. The change in thermal diffusivity of the films with the substrate temperature was analyzed. The optical bandgap values obtained from the photoacoustic spectroscopy were compared with the values obtained from the optical transmittance spectra. X-ray photoelectron spectroscopic (XPS) studies confirm the formation of stoichiometric films. Surface morphological studies by atomic force microscopy (AFM) revealed the crystalline nature of the films deposited at $100^{\circ} \mathrm{C}$.
\end{abstract}

PACS 68.60.Dv $\cdot 78.20 . \mathrm{Hp} \cdot 78.20 .-\mathrm{e}$

K. Jeyadheepan · C. Sanjeeviraja $(\bowtie)$

Department of Physics, Alagappa University, Karaikudi 630 003,

India

e-mail: sanjeeviraja@ rediffmail.com

P. Palanichamy

Nondestructive Evaluation Division, Indira Gandhi Centre

for Atomic Research, Kalpakkam 603 102, India

V. Swaminathan

School of Materials Science and Engineering, Nanyang

Technological University, Singapore 639 798, Singapore

M. Jayachandran

ECMS Division, Central Electrochemical Research Institute, Karaikudi 630 006, India

\section{Introduction}

$\mathrm{SnO}_{2}, \mathrm{In}_{2} \mathrm{O}_{3}$ and $\mathrm{ZnO}$ are good examples of degenerate semiconductors which are highly transparent and conducting binary metal oxide transparent conducting oxides (TCOs). These materials have been thoroughly investigated and employed in many applications. However, ternary oxide TCOs such as $\mathrm{Zn}_{2} \mathrm{SnO}_{4}$ [1], $\mathrm{CdIn}_{2} \mathrm{O}_{4}$ [2], $\mathrm{ZnGa}_{2} \mathrm{O}_{4}$ [3] and $\mathrm{Cd}_{2} \mathrm{SnO}_{4}$ [4] have eminent properties required for a transparent conducting oxide (TCO). Amongst these TCOs, n-type ternary $\mathrm{Cd}_{2} \mathrm{SnO}_{4}$ thin films show low electrical resistivity $\left(10^{-4} \Omega \mathrm{cm}\right.$ ), high transmission (>90\%) in the visible region and smoother surfaces than conventional $\mathrm{SnO}_{2} \mathrm{TCO}$ films [5, 6]. This aspect makes the $\mathrm{Cd}_{2} \mathrm{SnO}_{4}$ films an important material for the application of electrode material in solar photovoltaics.

Though much work has been reported on the electrical and optical properties of the material $\mathrm{Cd}_{2} \mathrm{SnO}_{4}$, to the best of our knowledge, no attempts have been made to understand its thermal properties in addition to the optical properties. Thermal properties like thermal diffusivity, thermal conductivity and the thermal effusivity of transparent conducting oxides (TCO) used in various applications must be determined very precisely and frequently. The thermal diffusivity is an important physical parameter that determines the heat transport through the material. This may be the essential condition of the proper choice of material and subsequently of the reliability and durability of the material. Since the thermal diffusivity is a parameter which depends closely on the microstructural variations, composition and the processing condition of the samples [7], it should be studied precisely. Photoacoustic spectroscopy (PAS) was used to study the thermal and also the optical properties of the transparent conducting $\mathrm{Cd}_{2} \mathrm{SnO}_{4}$ films. Though the photoacoustic technique has emerged as an important tool for 
the accurate evaluation of the thermal and optical properties of a large variety of materials, especially semiconductors $[8,9]$, the present report is an attempt to study the thermal and optical properties of the transparent conducting oxides (TCO) through photoacoustic spectroscopy.

The first report on the photoacoustic effect goes back to the eighteenth century when Bell [10] heard the sound generated by the sample that was illuminated with the modulated sunlight. Even though the first attempt of a modern theory of photoacoustics was made by Parker in 1973 [11], Rosencwaig and Gersho [12] derived the one-dimensional analysis of the production of photoacoustic signal in a simple cylindrical solid-gas interface system. Tominaga and Ito [13] proposed and Alvarado-Gil et al. [14] used the photoacoustic technique to study the thermal properties of the semiconductor (CdTe)-glass two layer system. This theory laid the basis to the photoacoustics to the thin film analysis. Marta et al. [15] used photoacoustic spectroscopy to determine the thickness of the multilayer thin films consisting of alternate layers of metal and oxide films prepared by magnetron sputtering technique. Raji et al. [16] made an attempt to deduce the thermal parameters of the nano $\mathrm{CdS}$ thin films through a photoacoustic technique. In the present study, an attempt was made to determine the thermal and optical properties of the RF sputtered $\mathrm{Cd}_{2} \mathrm{SnO}_{4}$ thin films using PAS. The optical bandgap values estimated from the photoacoustic spectra were also compared with the optical bandgap values estimated from the optical transmittance spectra.

\section{Experimental}

\subsection{Preparation of $\mathrm{Cd}_{2} \mathrm{SnO}_{4}$ thin films}

$\mathrm{Cd}_{2} \mathrm{SnO}_{4}$ films were deposited on glass substrates by $\mathrm{RF}$ magnetron sputtering from the target prepared from a wellblended mixture of the required quantities of $\mathrm{CdO}(99.99 \%$ pure) and $\mathrm{SnO}_{2}(99.99 \%$ pure) in the atomic weight ratio of $2: 1$. The RF power maintained in the HINDIVAC planar magnetron DC/RF sputtering unit (Hidhivac, Bangalore, India) was $200 \mathrm{~W}$. The sputtering chamber was evacuated to a base pressure of $6 \times 10^{-6} \mathrm{mbar}$ and was backfilled with pure argon up to the sputtering pressure of $5 \times 10^{-3}$ mbar and the sputtering pressure was maintained constant throughout the coating. The target to substrate distance was fixed at 6.5 $\mathrm{cm}$. The duration of the deposition was $30 \mathrm{~min}$ and the substrates were kept at room temperature (RT), $100^{\circ} \mathrm{C}, 200^{\circ} \mathrm{C}$ and $300^{\circ} \mathrm{C}$.

\subsection{Structural, optical and electrical characterization}

$\mathrm{X}$-ray diffraction (XRD) patterns were recorded using the PANalytical X'Pert PRO MPD diffractometer with $\mathrm{CuK}_{\alpha}$ radiation. The thickness of the films was measured with a Mitutoyo SJ-301 surface roughness tester. Optical transmittance spectra were recorded with Ocean Optics HR-2000 fiber optic spectrometer with the integration time of $5 \mathrm{~ms}$. Hall effect measurements were done using the Ecopia Hall effect measurement system model number HMS 3000.

\subsection{Surface characterization}

The surfaces of the RF magnetron sputtered $\mathrm{Cd}_{2} \mathrm{SnO}_{4}$ thin films were analyzed by atomic force microscopy for the surface morphology and with X-ray photoelectron spectroscopy (XPS) for the surface composition. Atomic force micrographs were obtained from the Veeco Digital Instruments DI-II with the silicon carbide tips in the contact mode to the surface of the films. The chemical composition and binding states of the cadmium tin oxide $\left(\mathrm{Cd}_{2} \mathrm{SnO}_{4}\right)$ thin films were characterized by $\mathrm{AlK}_{\alpha}$ radiation at $1.486 \mathrm{keV}$ using the ESCA 2000 spectrometer.

\subsection{Theoretical consideration and photoacoustic investigation}

The photoacoustic (PA) effect has been used for measuring the thermal properties of $\mathrm{Cd}_{2} \mathrm{SnO}_{4}$ samples. An open photoacoustic cell (OPC) configuration [17, 18] is employed in the heat transmission configuration in the present study. In the OPC configuration, the sample is enclosed in an air-tight cell with the electret microphone to keep the cell from the outside atmosphere. The sample is mounted on the top of the electret microphone, leaving a small air gap between the sample and the microphone. The sample is exposed to a chopped beam of polychromatic light. After absorption of light, it is converted into heat through nonradiative de-excitation processes. The pressure fluctuations produced in the gas which surrounded the sample and the microphone inside the OPC cell cause deflections on the microphone diaphragm, which generates the voltage in the output of the microphone. This voltage is fed to the lockin amplifier to record the signal amplitude and the phase with respect to the chopping reference of the light incident.

According to Rosencwaig-Gersho theory [12] the expression for the photoacoustic (PA) signal from 1-D heat flow model for a solid sample can be obtained as

$\delta P=\frac{P_{0} I_{0}\left(\alpha_{\mathrm{g}} \alpha_{\mathrm{s}}\right)^{1 / 2}}{2 \pi l_{\mathrm{g}} T_{0} k_{s} f \sinh \left(l_{\mathrm{s}} \sigma_{\mathrm{s}}\right)} \exp \left[j\left(\omega t-\frac{\pi}{2}\right)\right]$

Here $P_{0}$ is the ambient pressure, $T_{o}$ the ambient temperature, $I_{0}$ the absorbed light intensity and $\omega=2 \pi f$, where $f$ is the modulation frequency and $l_{i}, k_{i}$ and $\alpha_{\mathrm{s}}$ are the length (thickness), thermal conductivity and the thermal diffusivity of the sample, respectively. Here the $i=\mathrm{s}$ subscript denotes 
the sample and $i=\mathrm{g}$ denotes the gas medium. Also $\sigma_{\mathrm{s}}=$ $(1+j) a_{\mathrm{s}}$ where $a_{\mathrm{s}}=\left(\omega / 2 \alpha_{\mathrm{s}}\right)^{1 / 2}$ is the complex thermal diffusion coefficient of the sample.

If the sample is thermally thick, such that $l_{s} a_{s} \gg 1,(1)$ reduces to

$$
\begin{aligned}
\delta P \cong & \frac{P_{0} I_{0}\left(\alpha_{\mathrm{s}} \alpha_{\mathrm{g}}\right)^{1 / 2}}{\pi l_{\mathrm{g}} T_{0} k_{\mathrm{s}}} \frac{\exp \left[-l_{\mathrm{s}}\left(\pi f / \alpha_{\mathrm{s}}\right)^{1 / 2}\right]}{f} \\
& \times \exp \left[j\left(\omega t-\frac{\pi}{2}-l_{\mathrm{s}} a_{\mathrm{s}}\right)\right]
\end{aligned}
$$

Equation (2) means that, for a thermally thick sample, the amplitude of the PA signal decreases exponentially with the modulation frequency as $(1 / f) \exp (-a / \sqrt{f})$ and the phase decreases as $(-a / \sqrt{f})$, where $a=\left(\pi l_{s}^{2} / \alpha_{s}\right)^{1 / 2}$.

Hence, the thermal diffusivity $\alpha_{\mathrm{s}}$ can be obtained either from the amplitude data or from the phase data (PA depth profile analysis) by exponentially fitting it to the amplitude data or linearly fitting it to the phase data respectively. Knowing the coefficient ' $a$ ' from the fitting procedure, $\alpha_{\mathrm{S}}$ is readily obtained from

$\alpha_{\mathrm{s}}=\pi\left(\frac{l_{\mathrm{s}}}{a}\right)^{2}$

If the temperature gradient is generated within the sample along its thickness, there is a chance of thermoelastic bending (drum effect) [19] where the phase of the signal has the dependence of modulation frequency

$\phi=\phi_{0}+\tan ^{-1}\left[\frac{l}{l_{s}}\left(\frac{\pi f}{\alpha_{s}}\right)^{1 / 2}-1\right]$

In this case, thermoelastic bending is also to be considered. The thermoelastic bending effect could be dominant when the thickness of the sample is large and also when the thermal diffusivity of the samples is very low.

In the present photoacoustic spectroscopy experiment, a $450 \mathrm{~W}$ Xe-lamp (Horiba Jobin Yvon, USA) is used as the source. The sample (film + substrate) is placed in the photoacoustics (PA) cell and the mike is placed very close to the sample. To get modulated light, a mechanical chopper (C-995, Tetrahertz technologies Inc., USA) is used with the source. The PA signal from the microphone is fed to a lock-in amplifier (SR-830 DSP Stanford Research, USA). The light is allowed to fall on the sample through a monochromator (Triax 180, Horiba Jobin Yvon, USA) as shown in Fig. 1. The whole setup and the photoacoustic spectrometer is indigenously integrated and automated with the PC for the fastest data acquisition and better accuracy.

The depth profile analysis by PAS is carried out for two cases: (i) glass plate deposited with the film and (ii) glass plate alone (without the film). Firstly the glass plate with

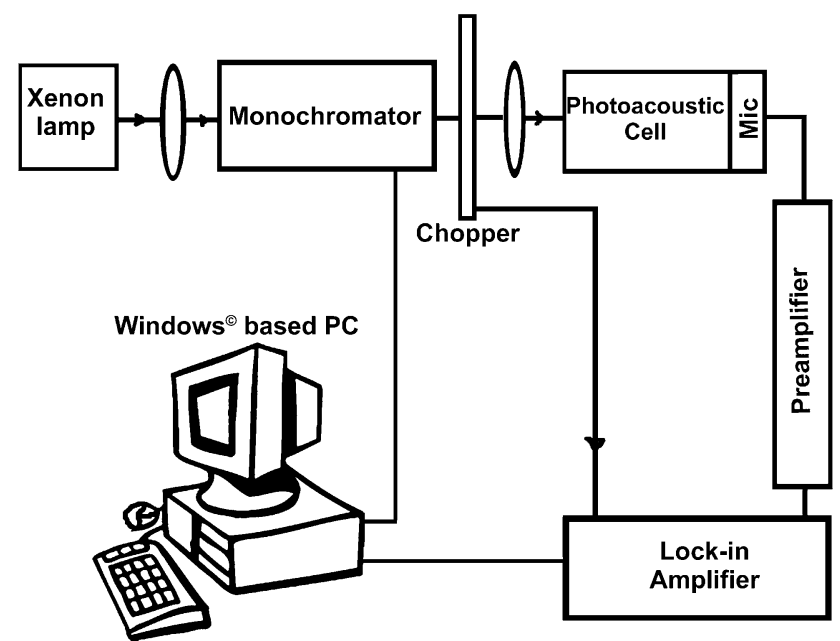

Fig. 1 Schematic diagram of the photoacoustic spectrometer

thin film deposited is taken inside the PA cell and the PA signal is observed for different chopping frequencies. Thermal diffusivity is then calculated for the sample from the slope ' $a$ ' of the curve for the thermally thick region, using (3). Since the film deposited on the glass substrate is used as the sample, the thermal diffusivity measured here will be the effective thermal diffusivity of glass plate and the film. Now for the glass plate alone, the PA signal was observed and with these data of thermal diffusivity of the glass plate $\left(\alpha_{\mathrm{g}}\right)$ and the effective thermal diffusivity $(\alpha)$, thermal diffusivity for the film alone $\left(\alpha_{\mathrm{s}}\right)$ is computed from the equation [13]

$\frac{l}{\sqrt{\alpha}}=\frac{l_{\mathrm{g}}}{\sqrt{\alpha_{\mathrm{g}}}}+\frac{l_{\mathrm{s}}}{\sqrt{\alpha_{\mathrm{s}}}}$

where $l_{\mathrm{g}}, l_{\mathrm{s}}$ are the thickness of glass and sample and $a_{\mathrm{g}}$ and $a_{\mathrm{s}}$ are their thermal diffusivities, respectively.

The optical bandgaps of the $\mathrm{Cd}_{2} \mathrm{SnO}_{4}$ thin films were estimated with a PA wavelength scanning experiment (photoacoustic spectrum), which is a measure of the PA intensity to the wavelength of the incident light keeping the chopping frequency constant, say $30 \mathrm{~Hz}$, in the present experiments. The PA spectrum measured for the sample $\left(\mathrm{Cd}_{2} \mathrm{SnO}_{4}\right)$ with the substrate was normalized with the PA spectrum of the glass to obtain the PA spectrum of the $\mathrm{Cd}_{2} \mathrm{SnO}_{4}$ film only. At photon energies above the bandgap, 'dips' will be there in the PA amplitude, which is evidence of resonant absorption via interband transitions [20]. From the dips, the optical bandgap can be directly found.

\section{Results and discussions}

Figure 2 shows the $\mathrm{X}$-ray diffraction patterns of the $\mathrm{Cd}_{2} \mathrm{SnO}_{4}$ films coated at room temperature (RT), $100^{\circ} \mathrm{C}, 200^{\circ} \mathrm{C}$ and 
$300^{\circ} \mathrm{C}$. The $\mathrm{XRD}$ analysis shows that the film coated on glass substrate maintained at RT was in its first state of crystallization. The small hump present in the diffraction data at $23.4^{\circ}$ is due to the glass substrate. The films prepared at $100^{\circ} \mathrm{C}, 200^{\circ} \mathrm{C}$ and $300^{\circ} \mathrm{C}$ were crystalline in nature having the cubic spinel phase. It is in good agreement with the results of Wang et al. [21]. The films coated at substrate temperatures $100^{\circ} \mathrm{C}, 200^{\circ} \mathrm{C}$ and $300^{\circ} \mathrm{C}$ were preferentially oriented along (311) plane.

The thickness of $\mathrm{Cd}_{2} \mathrm{SnO}_{4}$ thin films coated at substrate temperatures as $\mathrm{RT}, 100^{\circ} \mathrm{C}, 200^{\circ} \mathrm{C}$ and $300^{\circ} \mathrm{C}$ are tabulated

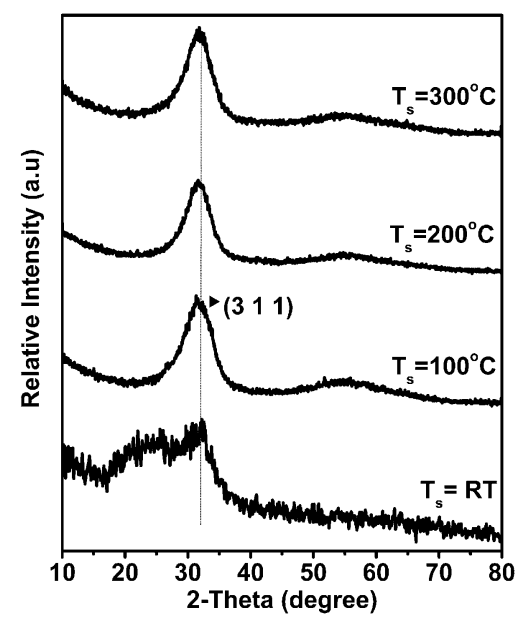

Fig. $2 \mathrm{X}$-ray diffraction patterns of the $\mathrm{Cd}_{2} \mathrm{SnO}_{4}$ thin films deposited at various substrate temperatures in Table 1. The thickness of the samples is in the range of one micrometer. The value of thickness is used for the calculation of the thermal diffusivity of the $\mathrm{Cd}_{2} \mathrm{SnO}_{4}$ films coated at various substrate temperatures.

Figure $3 \mathrm{a}$ and $\mathrm{b}$ shows the AFM micrographs of the $\mathrm{Cd}_{2} \mathrm{SnO}_{4}$ films coated at $\mathrm{RT}$ and $100^{\circ} \mathrm{C}$ respectively. The three-dimensional AFM images show that the room temperature coated films are amorphous in nature, whereas the films coated at $100^{\circ} \mathrm{C}$ consisted of grains with size in the nano meter range, which supports the results of the X-ray diffraction analysis. The rms roughness of the film coated with the substrate temperature of $100^{\circ} \mathrm{C}$ was about $9.16 \mathrm{~nm}$ whereas for the film coated at room temperature it was $5.93 \mathrm{~nm}$.

The chemical composition of the $\mathrm{Cd}_{2} \mathrm{SnO}_{4}$ films was characterized by XPS analysis, for the samples coated at RT and $300^{\circ} \mathrm{C} .5 \mathrm{~nm}$ of the material was sputtered off of the samples prior to XPS data collection, in order to remove the adsorbates on the surface due to the air exposure. Figure 4 shows the survey scan spectra of $\mathrm{Cd}_{2} \mathrm{SnO}_{4}$ thin films coated for different substrate temperatures. The measured binding energies of $\mathrm{Cd} 3 \mathrm{~d}_{5 / 2}, \mathrm{Cd} 3 \mathrm{~d}_{3 / 2}$, Sn $3 \mathrm{~d}_{5 / 2}$ and $\mathrm{Sn} 3 \mathrm{~d}_{3 / 2}$ in the $\mathrm{Cd}_{2} \mathrm{SnO}_{4}$ thin films are tabulated in Table 2. These values are well in agreement with the literature [22]. Quantitative XPS analysis was carried out by calculation of the area of $\mathrm{Cd} 3 \mathrm{~d}_{5 / 2}$ and $\mathrm{Sn} 3 \mathrm{~d}_{5 / 2}$ core level peaks of $\mathrm{Cd}_{2} \mathrm{SnO}_{4}$ thin films. The concentration ratio of $\mathrm{Sn} / \mathrm{Cd}$ was calculated from the equation $R=\frac{C_{\mathrm{Sn}}}{C_{\mathrm{Cd}}}$, where
Table 1 Thermal and optical results of $\mathrm{Cd}_{2} \mathrm{SnO}_{4}$ films deposited at various substrate temperatures

\begin{tabular}{llllll}
\hline $\begin{array}{l}\text { Substrate } \\
\text { temperature } \\
\left({ }^{\circ} \mathrm{C}\right)\end{array}$ & $\begin{array}{l}\text { Thickness } \\
\text { of the } \\
\mathrm{Cd}_{2} \mathrm{SnO}_{4} \\
\text { films }(\mu \mathrm{m})\end{array}$ & $\begin{array}{l}\text { Thermal } \\
\text { diffusivity } \\
\left(\times 10^{-6} \mathrm{~m}^{2} / \mathrm{s}\right)\end{array}$ & $\begin{array}{l}\text { Carrier } \\
\text { concentration } \\
\left(\times 10^{20} \mathrm{~cm}^{-3}\right)\end{array}$ & $\begin{array}{l}\text { Bandgap } \\
\text { measured } \\
\text { through } \\
\text { PAS }(\mathrm{eV})\end{array}$ & $\begin{array}{l}\text { Bandgap } \\
\text { obtained from } \\
\text { optical transmittance } \\
\text { spectra }(\mathrm{eV})\end{array}$ \\
\hline $\mathrm{RT}$ & $1.03(4)$ & $0.116(3)$ & 0.140 & $3.37(1)$ & $3.32(1)$ \\
100 & $0.99(5)$ & $1.053(3)$ & 6.980 & $3.09(2)$ & $3.07(1)$ \\
200 & $1.2(7)$ & $1.859(3)$ & 9.620 & $3.21(1)$ & $3.21(1)$ \\
300 & $1.04(4)$ & $1.973(3)$ & 13.41 & $3.29(1)$ & $3.30(1)$ \\
\hline
\end{tabular}

Fig. 3 Atomic force micrograph of the $\mathrm{Cd}_{2} \mathrm{SnO}_{4}$ thin films deposited at: a room temperature, $\mathbf{b} 100^{\circ} \mathrm{C}$

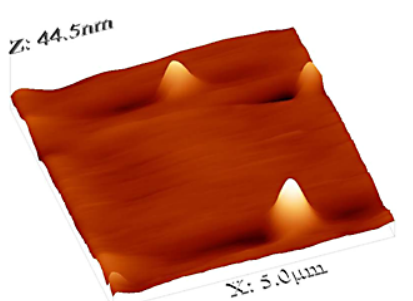

$\mathbf{a}$

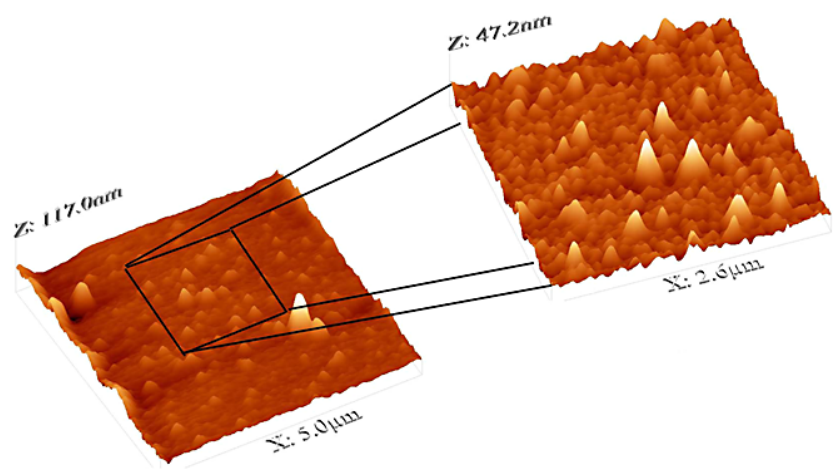

b 


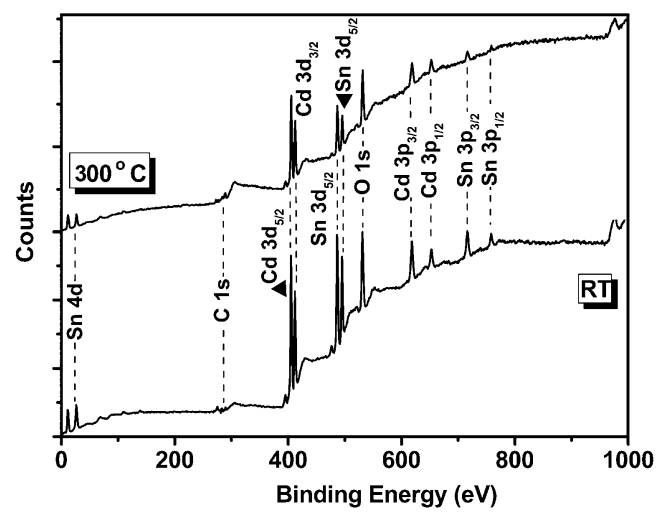

Fig. 4 Comparison of XPS survey scan spectra of $\mathrm{Cd}_{2} \mathrm{SnO}_{4}$ thin films deposited at different substrate temperatures

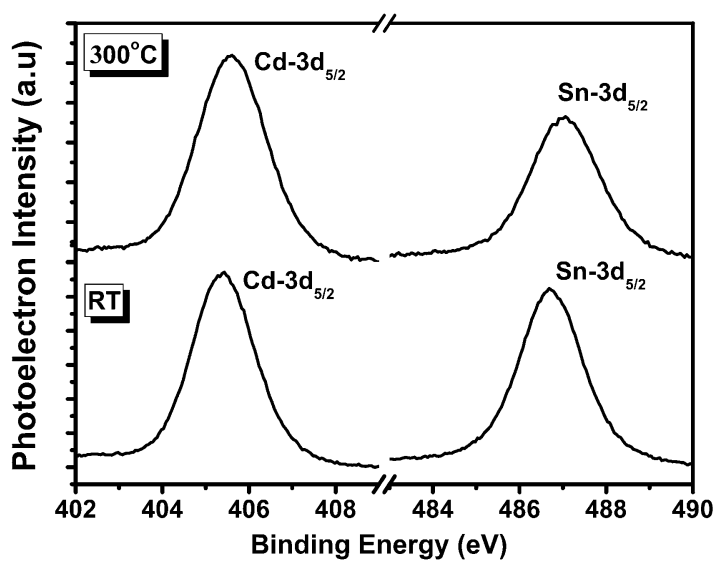

Fig. 5 Comparison of narrow scan XPS spectra of $\mathrm{Cd} 3 \mathrm{~d}_{5 / 2}$ and $\mathrm{Sn}$ $3 d_{5 / 2}$ of the $\mathrm{Cd}_{2} \mathrm{SnO}_{4}$ thin films

Table 2 Binding energies of Cd and Sn obtained from the XPS analysis

\begin{tabular}{lllll}
\hline Substrate temperature & ${\mathrm{Cd} 3 \mathrm{~d}_{5 / 2}}$ & ${\mathrm{Cd} 3 \mathrm{~d}_{3 / 2}}$ & $\mathrm{Sn} 3 \mathrm{~d}_{5 / 2}$ & $\mathrm{Sn} 3 \mathrm{~d}_{3 / 2}$ \\
\hline RT & 405.43 & 412.23 & 486.73 & 495.13 \\
$300^{\circ} \mathrm{C}$ & 405.61 & 412.41 & 487.05 & 495.46 \\
\hline
\end{tabular}

$C_{\mathrm{Cd}}=\frac{\frac{A_{\mathrm{Cd}}}{I_{\mathrm{Cd}}}}{\frac{A_{\mathrm{Cd}}}{T_{\mathrm{Cd}}}+\frac{A_{\mathrm{Sn}}}{T_{\mathrm{Sn}}}}, C_{\mathrm{Sn}}=\frac{\frac{A_{\mathrm{Sn}}}{I_{\mathrm{Sn}_{\mathrm{n}}}}}{\frac{A_{\mathrm{Cd}}}{I_{\mathrm{Cd}}}+\frac{A_{\mathrm{Sn}}}{I_{\mathrm{Sn}}}}, A_{\mathrm{Cd}}$ and $A_{\mathrm{Sn}}$ are the area measured under the $\mathrm{Cd} 3 \mathrm{~d}_{5 / 2}$ and $\mathrm{Sn} 3 \mathrm{~d}_{5 / 2}$ peaks respectively, and $I_{\mathrm{Cd}}$ and $I_{\mathrm{Sn}}$ are the ionization cross sections for the particular shells of cadmium and tin, respectively. Figure 5 shows the narrow scan XPS spectra of the $\mathrm{Cd} 3 \mathrm{~d}_{5 / 2}$ and $\mathrm{Sn} 3 \mathrm{~d}_{5 / 2}$ of the $\mathrm{Cd}_{2} \mathrm{SnO}_{4}$ thin films coated at room temperature and $300^{\circ} \mathrm{C}$. The ratio of $\mathrm{Sn} / \mathrm{Cd}$ in the $\mathrm{Cd}_{2} \mathrm{SnO}_{4}$ thin films coated at room temperature and at $300^{\circ} \mathrm{C}$ was determined to be 0.74 and 0.57 . XPS analysis results show that the near-stoichiometric films can be produced at higher substrate temperature.
The plots of PA phase versus the square root of modulation frequency of the light for $\mathrm{Cd}_{2} \mathrm{SnO}_{4}$ thin films coated at the substrate temperature of RT, $100^{\circ} \mathrm{C}, 200^{\circ} \mathrm{C}$ and $300^{\circ} \mathrm{C}$ are shown in Fig. 6. It is clear from the figure that there is a curvature indicating the evidence of thermoelastic bending. Since the thickness of the sample is very low, the pronounced thermoelastic bending is due to the much lower value of the thermal diffusivity of the $\mathrm{Cd}_{2} \mathrm{SnO}_{4}$ thin films. This makes $\mathrm{Cd}_{2} \mathrm{SnO}_{4}$ thin films a candidate with good reliability and it keeps the durability of the photovoltaic materials in which the $\mathrm{Cd}_{2} \mathrm{SnO}_{4}$ films are used as the transparent electrodes. The thermoelastic bending also depends on the degree of crystallinity of the sample [23]. However, since the $\mathrm{R}-\mathrm{G}$ theory is valid for the thermally thick regime, the curve was fitted to the higher modulation frequency region to obtain the thermal diffusivity.

The thermal diffusivity of the $\mathrm{Cd}_{2} \mathrm{SnO}_{4}$ thin films coated at room temperature (RT), $100^{\circ} \mathrm{C}, 200^{\circ} \mathrm{C}$ and $300^{\circ} \mathrm{C}$ was calculated through the photoacoustic spectroscopy with an accuracy of $\pm 0.0032 \times 10^{-7} \mathrm{~m}^{2} / \mathrm{s}$. The calculated thermal diffusivity is tabulated in Table 1 and is shown in Fig. 7 as a function of the substrate temperature. Since no other experimental data of thermal diffusivity $\left(\alpha_{\mathrm{s}}\right)$ are available in the literature for $\mathrm{Cd}_{2} \mathrm{SnO}_{4}$ thin films; we cannot compare our results with others. The photoacoustic depth profiling measurements gave away that the thermal diffusivity increases with increase in substrate temperature. The increase in the thermal diffusivity with the substrate temperature may be due to the increase in the degree of crystallinity of $\mathrm{Cd}_{2} \mathrm{SnO}_{4}$ thin films. As the crystallinity of the samples increases with the substrate temperature, there may be a decrease in lattice distortion [24]. This further pronounces the decrease in phonon scattering due to the decrease in the grain boundary scattering, resulting in the increase in the thermal diffusivity of the samples.

The PA spectra of the $\mathrm{Cd}_{2} \mathrm{SnO}_{4}$ thin films coated at various substrate temperatures were shown in Fig. 8. From the origin of the absorption (dips), the optical bandgap values are obtained. The optical bandgap values are also measured from the optical transmittance measurements which were obtained from the optical transmittance spectra (Fig. 9a). The plot of $(\alpha h \gamma)^{2}$ against $h \gamma$ for all the samples is shown in Fig. 9b. The optical bandgap values obtained from the photoacoustic measurements were compared with the optical bandgap values measured from the optical transmittance measurements (Fig. 10).

The optical transmittance spectra show that the $\mathrm{Cd}_{2} \mathrm{SnO}_{4}$ thin films were highly transparent in nature as its transparency is about $90 \%$. The optical bandgap values estimated from the PA spectra and also from the optical transmittance spectra increase with the increase in substrate temperature. But for the samples coated at $100^{\circ} \mathrm{C}$ they show a significant decrease in optical bandgap. This is due to the noteworthy increase in the crystallinity of the samples coated 
Fig. 6 Plots of PA phase as a function of the square root of the modulation frequency for the $\mathrm{Cd}_{2} \mathrm{SnO}_{4}$ thin films deposited at a RT b $100^{\circ} \mathrm{C}$ c $200^{\circ} \mathrm{C}$ d $300^{\circ} \mathrm{C}$
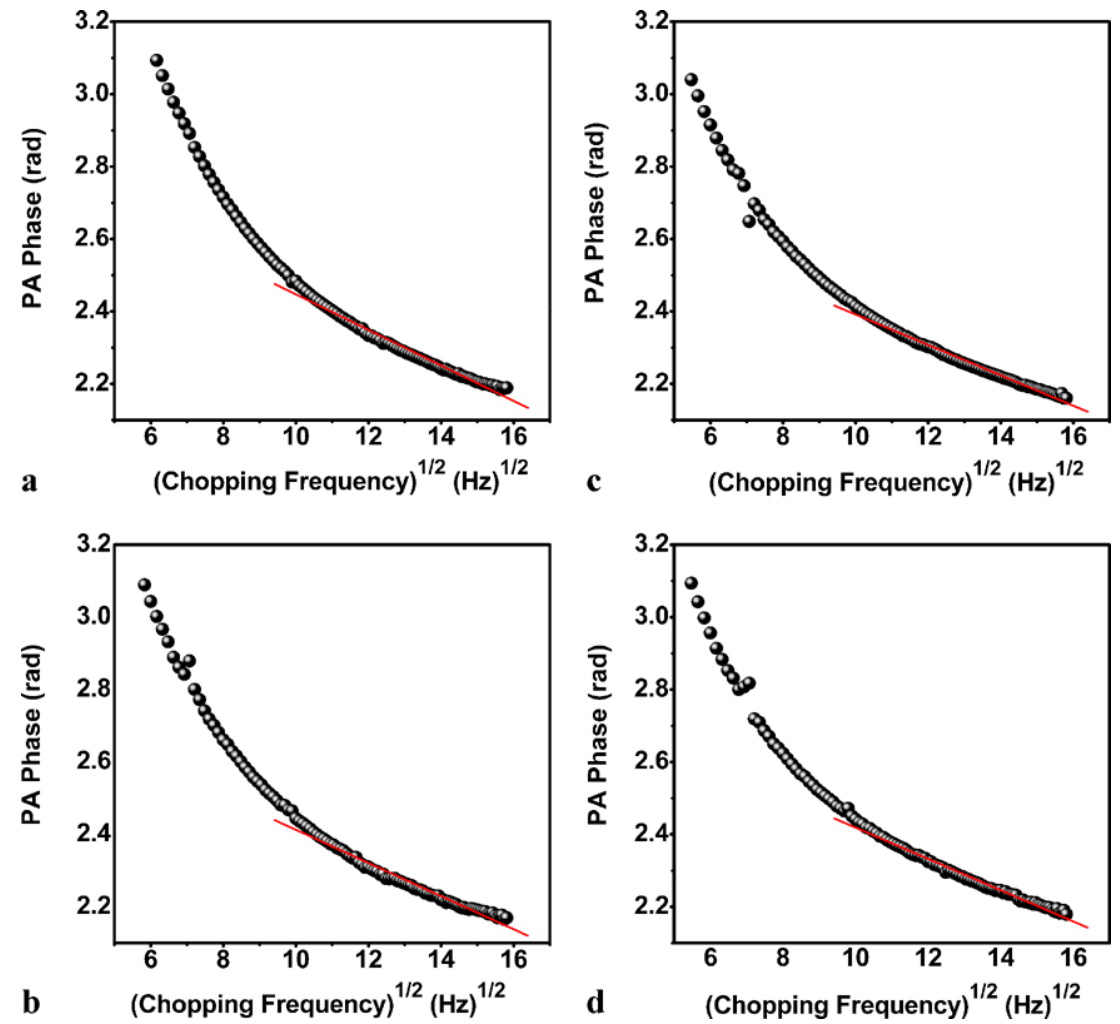

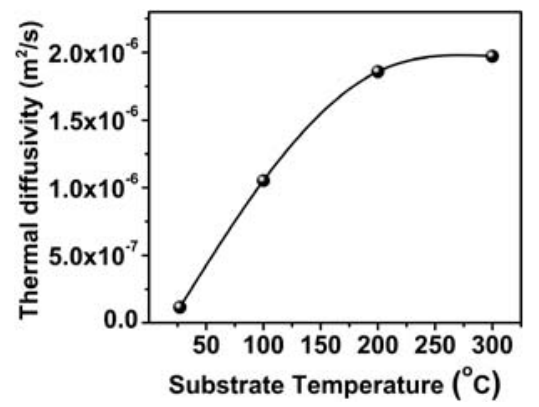

Fig. 7 Thermal diffusivity of $\mathrm{Cd}_{2} \mathrm{SnO}_{4}$ films deposited at various substrate temperatures

at $100^{\circ} \mathrm{C}$ when compared to the RT coated samples, which are amorphous, explained by X-ray diffraction analysis and AFM analysis. When the substrate temperature is increased from $100^{\circ} \mathrm{C}$ to $300^{\circ} \mathrm{C}$, the bandgap is shifted to the higher energy region related to the Moss-Burstein effect, which is due to the increase in the carrier concentration [25]. Our Hall effect measurements showed that the carrier concentration was increased from $0.140 \times 10^{20}$ to $13.41 \times 10^{20} \mathrm{~cm}^{-3}$ with increasing substrate temperature. According to Segev et al. [26], when the system is n-type doped, the optical transition can occur between the conduction band minimum (CBM) and states with energy higher than the CBM energy, for $k$ points away from the Brillouin zone center. The energy of the transition between the first conduction band and the other conduction band decreases with increasing car-

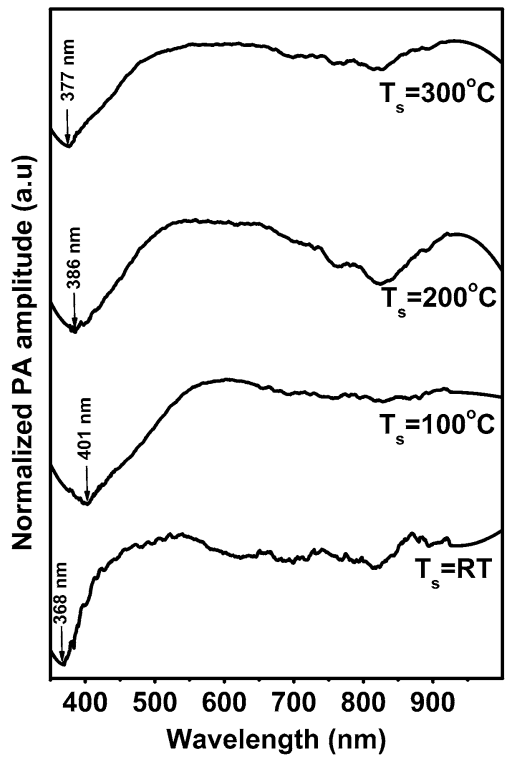

Fig. 8 PA spectra of the $\mathrm{Cd}_{2} \mathrm{SnO}_{4}$ thin films deposited at room temperature $\left(27^{\circ} \mathrm{C}\right), 100^{\circ} \mathrm{C}, 200^{\circ} \mathrm{C}$ and $300^{\circ} \mathrm{C}$

rier concentration. Our results showed an increase in optical bandgap with the substrate temperature, which may be mainly due to the Moss-Burstein shift. Our results make evident the theoretical predictions of Segev et al. [26] that the Moss-Burstein shift (apparent bandgap) as a result of transitions from valence band states to unoccupied conduc- 


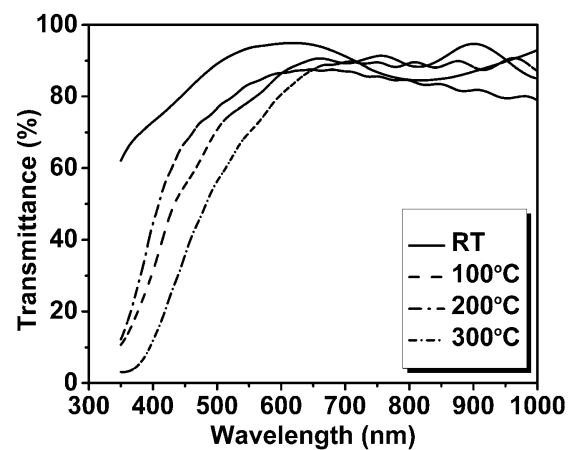

a

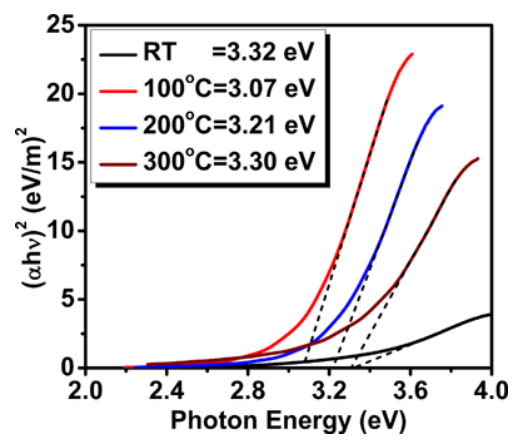

b

Fig. 9 a Optical transmittance spectra of $\mathrm{Cd}_{2} \mathrm{SnO}_{4}$ thin films deposited at various substrate temperatures. b Plot of $(\alpha h \gamma)^{2}$ versus photon energy $(h \gamma)$

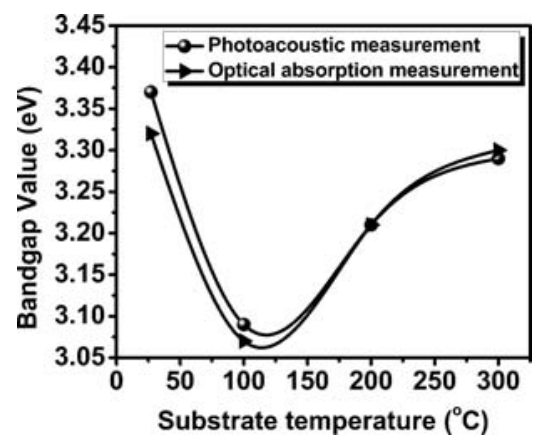

Fig. 10 Comparison of optical bandgap values obtained from PA and optical transmittance measurements

tion states, away from the Brillouin zone center, causes an increase in the optical bandgap, when measured by optical absorption spectroscopy and also by photoacoustic spectroscopy.

\section{Conclusion}

Broad bandgap $\mathrm{Cd}_{2} \mathrm{SnO}_{4}$ thin films were prepared with a high degree of transparency $(\sim 90 \%)$. The photoacoustic analysis made on the samples shows that the substrate temperature significantly affects the material properties of $\mathrm{Cd}_{2} \mathrm{SnO}_{4}$ thin films. Photoacoustic spectroscopic measurements made on the $\mathrm{Cd}_{2} \mathrm{SnO}_{4}$ films for thermal and optical properties are more reliable than any other methods: because of the non-destructive technique the sample is not damaged. The PA analysis results provide optical bandgap values that are very close to values calculated from optical transmission studies. Our results suggest that photoacoustic spectroscopy can be used to find the optical bandgap of the transparent conducting oxides also.

\section{References}

1. J.X. Wang, S.S. Xie, Y. Gao, X.Q. Yan, D.F. Liu, H.J. Yuan, Z.P. Zhou, L. Song, L.F. Liu, W.Y. Zhou, G. Wang, J. Cryst. Growth 267, 177 (2004)

2. R.D. Shannon, J.L. Gillson, R.J. Bouchard, J. Phys. Chem. Solids 38, 877 (1977)

3. T. Omata, N. Ueda, K. Ueda, H. Kawazoe, Appl. Phys. Lett. 64, 1077 (1994)

4. X. Wu, W.P. Mulligan, T.J. Coutts, Thin Solid Films 286, 274 (1996)

5. T.J. Coutts, D.L. Young, X. Li, W.P. Mulligan, X. Wu, J. Vac. Sci. Technol. A 18, 2646 (2000)

6. X. Wu, T.J. Coutts, U.S. Patent No. 6221495, 2001

7. K. Raveendranath, J. Ravi, S. Jayalekshmi, T.M.A. Rasheed, K.P.R. Nair, Mater. Sci. Eng. B 131, 210 (2006)

8. O. Delgado-Vasallo, A.C. Valdes, E. Marin, J.A.P. Lima, M.G. da Silva, M. Sthel, H. Vargas, S.L. Cardoso, Meas. Sci. Technol. 11, $412(2000)$

9. W.M.M. Yunus, C.Y.J. Fanny, T.E. Phing, S.B. Mohammed, S.A. Halim, M.M. Moksin, J. Mater. Sci. 37, 1055 (2002)

10. A.G. Bell, Am. J. Sci. 20, 305 (1880)

11. J.G. Parker, Appl. Opt. 12, 2974 (1973)

12. L.F. Perondi, L.C.M. Miranda, J. Appl. Phys. 62, 2955 (1987)

13. T. Tominaga, K. Ito, Jpn. J. Appl. Phys. 27, 2392 (1988)

14. J.J. Alvarado-Gil, O. Zelaya-Angel, F. Sánchez-Sinencio, H. Vargas, J.L. Lucio, Vacuum 46, 883 (1995)

15. M.M.D. Ramos, J.A. Ferreira, M. Isabel, C. Ferreira, M.P. dos Santos, Vacuum 39, 731 (1989)

16. P. Raji, C. Sanjeeviraja, K. Ramachandran, Bull. Mater. Sci. 28, 233 (2005)

17. G.M. Sessler, J.E. West, in Electrets, ed. by G.M. Sessler. Springer Series on Topics in Applied Physics, vol. 33 (Springer, Berlin, 1980), p. 347

18. P. Halander, J. Appl. Phys. 59, 3339 (1986)

19. L.F. Perondi, L.C.M. Miranda, J. Appl. Phys. 62, 2955 (1987)

20. D. Almond, P. Patel, Photothermal Science and Techniques, 1st edn. (Chapman \& Hall, London, 1996), pp. 129

21. W.L. Wang, K.J. Liao, C.Z. Cai, G.B. Liu, Y. Ma, Surf. Coat. Tech. 167, 284 (2003)

22. W. Wohlmuth, I. Adesida, Thin Solid Films 479, 223 (2005)

23. S.M. Souza, C.E.M. Campos, J.C. de Lima, T.A. Grandi, P.S. Pizani, Solid State Commun. 139, 70 (2006)

24. T.J. Richardson, S.J. Wen, K.A. Strichel, P.N. Ross Jr., E.J. Cairns, Mater. Res. Bull. 32, 609 (1997)

25. R. Mamazza Jr., D.L. Morel, C.S. Ferekides, Thin Solid Films 484, 26 (2005)

26. D. Segev, S.-H. Wei, Phys. Rev. B 71, 125129 (2005) 